\title{
SPATIAL DISTRIBUTION AND SHOALING BEHAVIOUR OF FISHERY RESOURCES IN THE WATERS OFF WESTERN COAST OF ACEH: PRELIMINARY RESULTS FROM THE POST TSUNAMI EXPEDITION 2005
}

\author{
Wijopriono"), Mohamad Natsir"), Aril Slotte"), and Asep Priatna")
}

\begin{abstract}
Acoustic investigation, which is one of the programmes of the Post Tsunami Expedition, was done in Aceh waters during 24 July to 14 August 2005. Research vessel Bawal Puth I and Baruna Jaya VIII were used for the survey. The objective of this survey is to obtain pelagic fish resources distribution, after the area hit by tsunami at the end of 2004. Two different models and frequencies were used in acquisition of the data; SIMRAD EK-500 Scientific Echosounder with $38 \mathrm{kHz}$ splitbeam transducer (Baruna Jaya VIII) and Simrad EK-60 scientific echosounder with $120 \mathrm{kHz}$ splitbeam transducer (Bawal Putih I). Results show that fish aggregations appeared in high density layers in deep waters all over the study area. Fish shoals occurred in relation to topographic features such as shelf edges and deep valleys. On the shelf, fish schoals tend to stay close to the bottom during daytime, while it raised, with more fish shoals were observed, during night time. More abundance prevails in areas of rough bottom conditions where trawl fishing was not possible, specifically in north areas between Lhok Nga and Calang. Abundances of fish in the coastal area off Sibolga seem to be relatively lower compared with those in its northern part.
\end{abstract}

KEYWORDS:

fishery resources, abundance, hydro acoustics, post Tsunami, western coast of Aceh

\section{INTRODUCTION}

Traditionally, fish distribution, and abundance may be indirectly estimated through analysis of historical data on fish catch per unit effort or through the statistical analysis of mark recapture experiments using tagged fish. However, these indirect methods are often biased not only by the selectivity of fishing gear and by artificial on the economic ground, but also by means of communication between fishermen and researchers on the information of catch data. In addition, considerable time, and substantial efforts are required in estimating fish distribution and abundance by the statistical analysis on the historical data.

Following the advance development of hydro acoustic technology, sonar and echosounder have a major impact on fisheries, especially their application in fishing system, such as searching for profitable concentration of fish. In fisheries research, it has become increasingly importance over the years for studying and monitoring distribution, congregation, and migration of fish (Engas \& Ona, 1987; Misund, 1987; Thorne et al., 1987).

Hydro acoustic method can be considered as on of the suitable methods for estimating fish abundance directly. The procedure involves echo sounding along a transect area and measuring the return echo intensity. A calibrated hydro-acoustic system then provides an estimate of the fish biomass for specified depth and distance intervals along the transect area (Burczynski, 1982).

A programme of the investigation of tsunami effects on marine life in Aceh and North Sumatera was carried out during July to August 2005. Research vessel Bawal Putih I and Baruna Jaya VIII were commissioned to survey the fisheries resources, mainly those of the waters off west and north coast of Aceh that was severely hit by tsunami. Acoustic and exploratory fishing survey were done to meet the objective. Acoustic system observed fish biomass, depth, and bottom topography, while fishing system observed catch, species, fish size and composition, and fish biological data. Oceanographic data were also collected during the survey. This paper discuss specifically on the preliminary results of the acoustic survey, which are related to the spatial distribution and shoaling behaviour of pelagic fish resources.

\section{MATERIALS AND METHODS}

\section{Description of Acoustic Equipment}

Acoustic data acquisition was conducted simultaneously with bathymetric transect. Two different models and frequencies were used in acquisition of the data; SIMRAD EK-500 Scientific

\footnotetext{
* Research Institute for Marine Fisheries, Muara Baru-Jakarta

*) Institute of Marine Research, Bergen, Norway
} 
Echosounder with $38 \mathrm{kHz}$ splitbeam transducer was used for data acquisition onboard of R/V Baruna Jaya VIII, while Simrad EK-60 scientific echosounder with $120 \mathrm{kHz}$ splitbeam transducer was used for data acquisition onboard of RN Bawal
Putih I. Before the survey the equipment was calibrated using $60 \mathrm{~mm}$ copper standard target according standard procedures from Foote et al. (1987). The acoustic parameters setting for both of the EK-500 and $\mathrm{BI}-60$ is showed in Table1.

Table 1. Parameter setting from EK 60 and EK 500 during the survey

\begin{tabular}{lcc}
\hline \multicolumn{1}{c}{ Parameter } & EK-60 & EK-500 \\
\hline Frequency & $120 \mathrm{KHz}$ & $38 \mathrm{KHz}$ \\
Pulse Duration & $0.512 \mathrm{~ms}$ & Medium \\
Power transmit & $500 \mathrm{Watt}$ & $2,500 \mathrm{Watt}$ \\
Sound speed & $1500 \mathrm{~m} / \mathrm{s}$ & $1,500 \mathrm{~m} / \mathrm{s}$ \\
Absorption Coefficient & $41.80 \mathrm{~dB} / \mathrm{km}$ & $10.0 \mathrm{~dB} / \mathrm{km}$ \\
SV threshold & $-90 \mathrm{~dB}$ & $-90 \mathrm{~dB}$ \\
TS threshold & $-60 \mathrm{~dB}$ & $-60 \mathrm{~dB}$ \\
\hline
\end{tabular}

Acoustic data were collected within the entire water column. However, in the deep waters the data were recorded only from the surface down to maximum of $750 \mathrm{~m}$. Echo integration was performed by $25 \mathrm{~m}$ depth layers. Acoustic samples (echo integrations, echograms) were collected continuously 24 hours a day, and acquired within the path of the vessel along the designed transect lines with the vessel's speed at 6 to 7 knot. The ESDU (elementary sampling distance unit the distance over which the echo integral is accumulated to give one sample) was 1 nautical mile (nmi). Acoustic data stored on the hard disk and dedicated softwares, BI-500 (Baruna Jaya VIII) and $\mathrm{BI}-60$ (Bawal Putih I) were used for scrutinizing echo signals.

Basically, the integrator performs integration in the vertical direction within the layers and averaging in the horizontal direction along the path traveled by the vessel. The integration process is based on the quantity $10 \log (\mathrm{Sv})$ and is defined by the equation as follows:

$$
\begin{aligned}
& \frac{\partial \sigma}{\partial v}=4 \pi r_{0}^{2} S v \ldots . \\
& \frac{\partial \sigma}{\partial A}=\int_{r 1}^{r 2} \frac{\partial \sigma}{\partial v} d r \\
& \sigma_{A}=\text { Mean } \frac{\partial \sigma}{\partial A} \ldots .
\end{aligned}
$$

The first equation converts volume back scattering strength to back scattering area per unit of volume. The corresponding back scattering area per unit of horizontal area is obtained by integrating over the layer vertically, $r_{1}$ to $r_{2}$. The output parameter from the integrator each averaging interval $\sigma_{A}$ represents the mean back scattering area per unit horizontal area and is obtained by averaging the individual $\partial \sigma / \partial_{A}$ 's over one interval. The quantity $S_{A}\left(m^{2} \mathrm{~nm}^{-2}\right)$ is related to $\sigma_{A}\left(m^{2} \mathrm{~nm}^{-2}\right)$ as:

$\mathrm{S}_{\mathrm{A}}=(1852 \mathrm{~m} / \mathrm{nm})^{2} \sigma_{\mathrm{A}}$

The algorithm implemented by the sounder is obtained by combining the four equations:

$$
S_{A}=4 \pi r_{0}^{2}\left[{ }^{r_{2}}[S v d r](1852 \mathrm{~m} / \mathrm{nm})^{2}\right.
$$

\section{Scrutinizing}

Given the fact that sampling of the acoustic registrations (through trawl fishing operation) was impossible, especially in the offshore areas, it was also impossible to scrutinize data into species. However, based on the characteristics of layers and targets strength distributions, an attempt was made to scrutinize the recorded data into 5 different groups; 1) plankton, 2) presumed fish schools, 3) presumed fish and plankton mixed in specific layers, 4) presumed plankton and fish mixed dispersed in the water column, and 5) presumed plankton and fish in a dispersed mix in the water column including acoustic noise'. The recorded area echo abundance, i.e. the nautical area backscattering coefficient (NASC), $S_{A}$ (MacLennan, 1990), was influenced by acoustic noise from the vessel or from other equipment. As far as possible this noise was manually removed. However, in large parts of the survey the noise was simply too much to remove manually, and hence these data 
were put into group 5. During very detailed multibeam acoustic mapping, only parts of the survey were scrutinized.

\section{RESULTS AND DISCUSSION}

Investigations of R/V Bawal Putih I were mostly limited to the narrow continental shelf, i.e. the area of 20 to $200 \mathrm{~m}$ bottom depth, in the waters of north and west coast of Nangroe Aceh, whereas Baruna Jaya VIII went to a larger degree covered the deeper parts along and off the shelf. The acoustic density varied geographically in the study area, being higher along and off the shelf than on the shelf itself. The highest values were recorded off Banda Aceh (Figure 1). The acoustic density tended to increase at nighttime, with up to 4 times higher values (Figure 2). At the same time there was a shift in the depth of highest density from 0 to $25 \mathrm{~m}$ to 75 to $100 \mathrm{~m}$ (Figure 3). Target strength data indicated that this increase was due to fish migrating towards the surface from deeper parts mixing with plankton at a layer just above the thermocline at ca. 100 depths (Figure 4).

Fish was observed in deep layers at 300 to 450 $m$ depth all over the studied area. Note that in areas with depth less than $400 \mathrm{~m}$ the layer appeared to undertake vertical migrations towards the plankton layer closer to surface ( 0 to $100 \mathrm{~m}$ depth), whereas in deeper areas (depth>400 m) the layer appeared to stay at the same depth regardless of the diurnal cycle (Figure 5). This may imply that we are talking about two different species with different behaviour, or it may be a difference between young and adult fish we are seeing. In temperate waters it is common for the young fish of pelagic resources (blue whiting, herring, mesopelagic fish) to undertake migrations towards the surface at nighttime, whereas the adults maintain their position in the deep (Slotte et al., 2004). If these presumed fish layers and their behaviour have not been previously studied, it is certainly an interesting subject for future investigations.

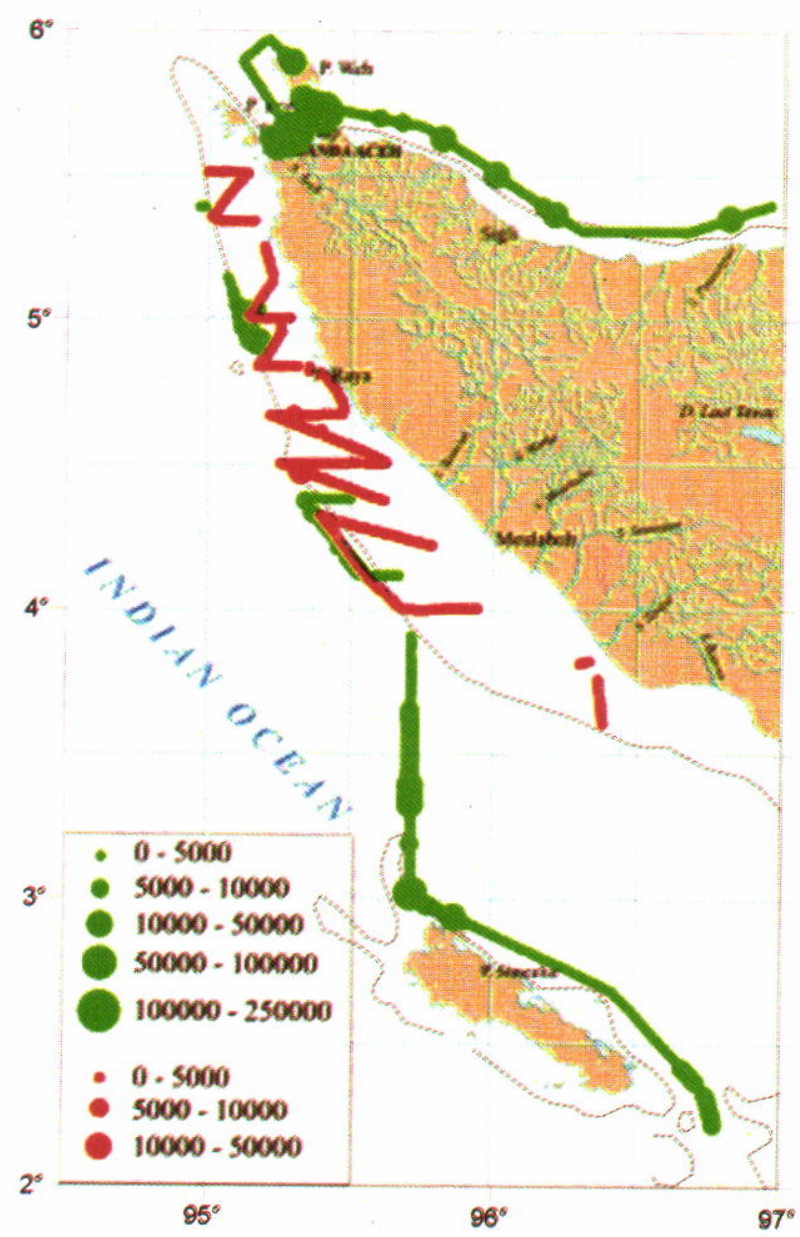

Figure 1. The acoustic density (in unit of $S_{A}$ ) along the survey tracks of Baruna Jaya VIII (green) and Bawal Putih (red). 


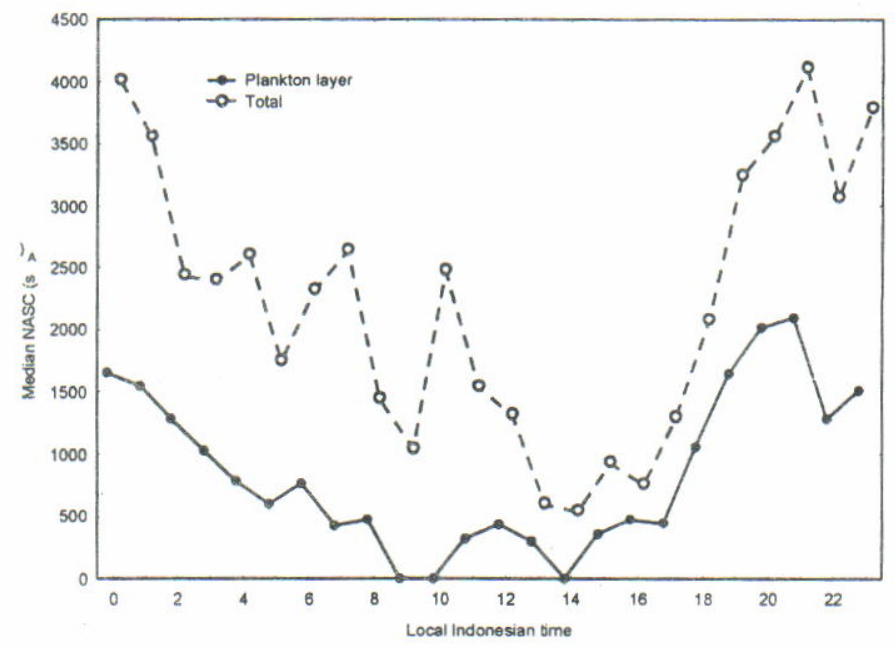

Figure 2. Diurnal changes in Acoustic density (in unit of $S_{A}$ ) along the survey tracks of Baruna Jaya VIII.
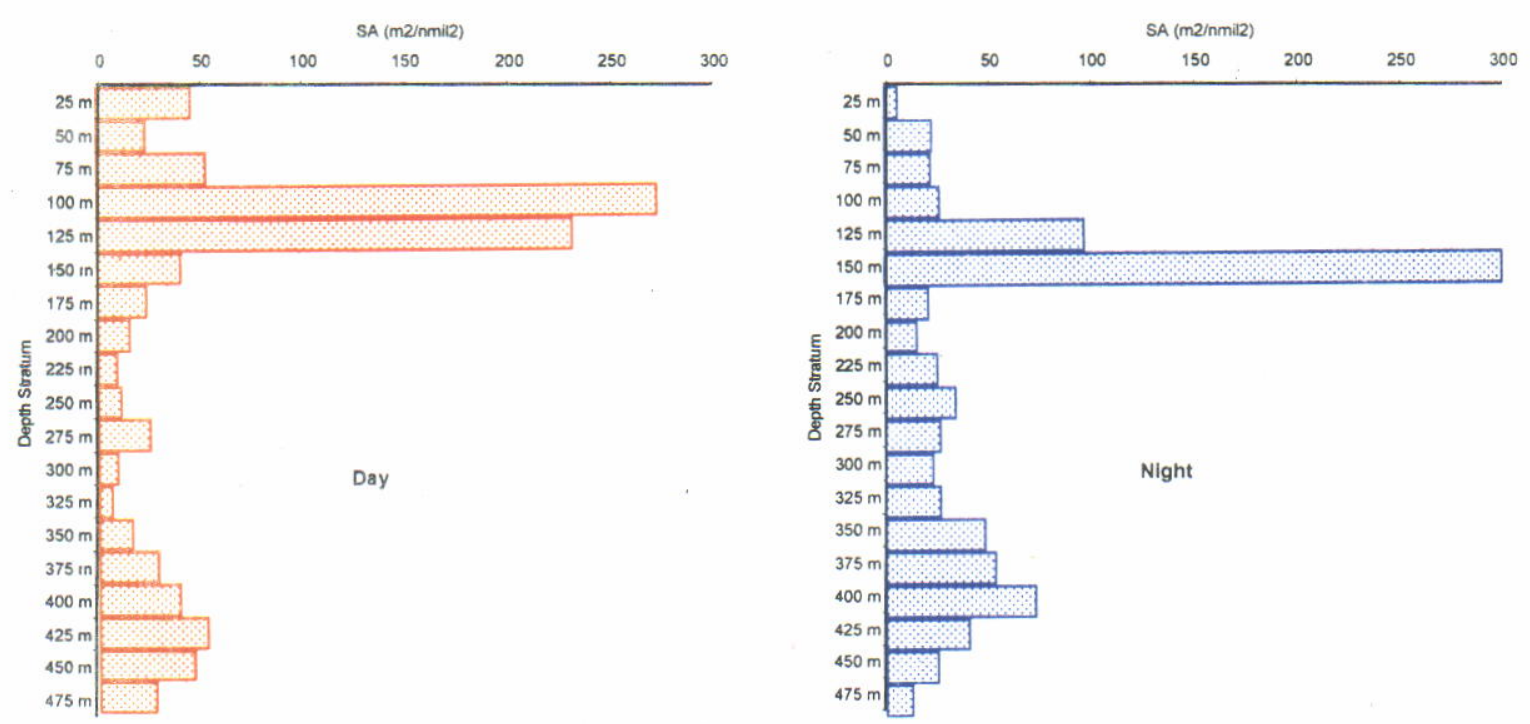

Figure 3. Acoustic density (volumetric density) by depth along the survey track of Baruna Jaya VIII; comparison between day and night.

Fish shoals were observed in all the three main areas. Most of the shoals were observed off Banda Aceh, and typically they were observed in connection with the shelf break (Figure 6). They appeared to be two different type of schools: 1) the really big shoals with high densities peaking at more than 200.000 in $1 \mathrm{nmi}$ NASC values, staying close to the bottom at around 125 to $150 \mathrm{~m}$ depth just below the shelf break; and 2) The more loose shoals of less density appearing from the surface and down to $75 \mathrm{~m}$ depth, appearing along the shelf break, but also to some extent on the shelf itself. If these presumed fish shoals and their behaviour have not been previously studied, it also an interesting subject for future projects in which the use of sonar equipment for shoal tracking may be very valuable. The really big schoals in the deeper part deserve some special attention.

Also off the Lhok $\mathrm{Nga}$ barrier reef at the presumed fish schools typically appeared along the shelf break (Figure 7), two different kinds of presumed fish shoals were observed: 1) quite loose shoals almost appearing like a layer at some distance from the shelf, which seemed to under take some kind of vertical migration related to the diurnal cycle, staying close to the bottom at 200 to $250 \mathrm{~m}$ dept during daytime and mixing with the plankton layer at 0 to $100 \mathrm{~m}$ depth during darkness. The acoustic response from these shoals was 


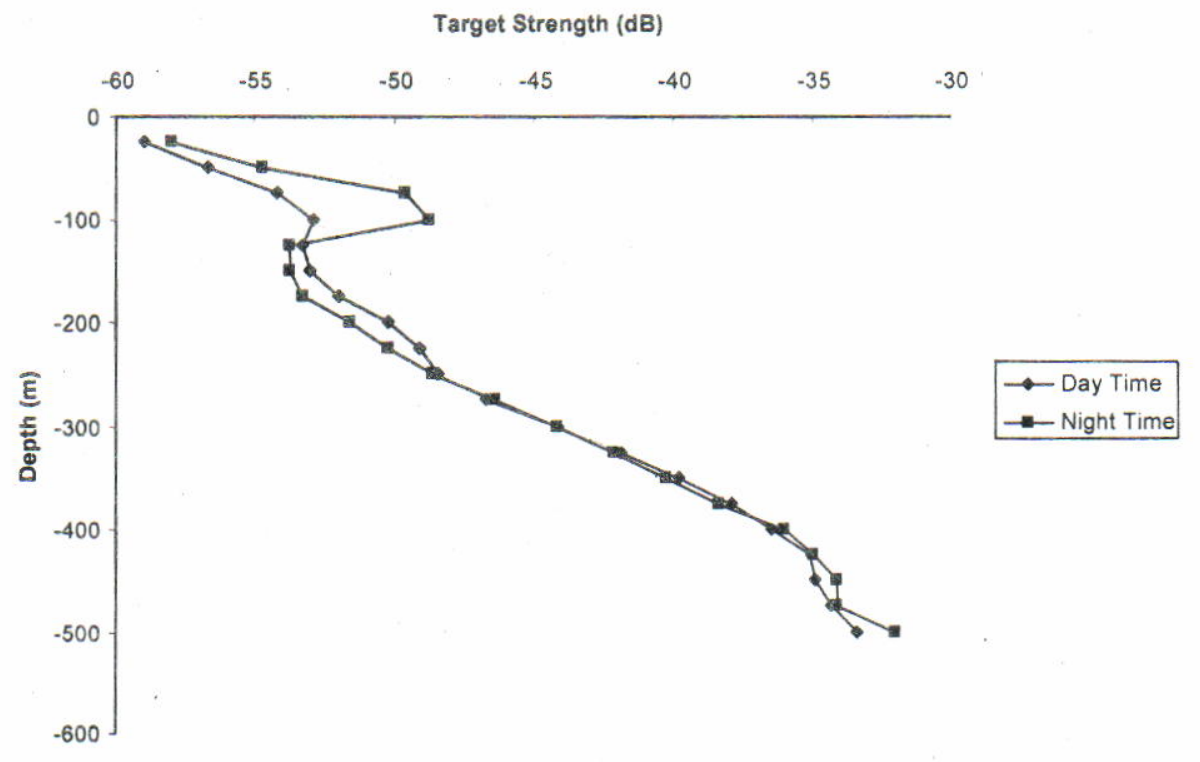

Figure 4. Average target strength by depth along the survey track of Baruna Jaya; comparison between day and night.

higher at the $120 \mathrm{kHz}$, which is not common for fish with swim bladders, whereas it is common for fish without swim bladder, as in mackerel. Denser shoals typically appeared at 100 to $250 \mathrm{~m}$ depth along the shelf, and in the deep channel entering the shelf.

Off Simeuleue less time was used to cover the area, and only a few relatively loose shoals were observed along the shelf (Figure $8 \mathrm{a}$ and $8 \mathrm{~b}$ ), at 150 to $200 \mathrm{~m}$ depths. However, note that in this area, opposite to areas 1 to 2, several shoals of large fish were observed hunting at the surface.

The acoustic data from Bawal Putih I demonstrate that coral reefs and rocks dominated most of sea bottom of northern area off the west coast, and made up a hindrance for bottom trawl operation (Figure 9). Pelagic fish schools on the shelf were appeared more often along the acoustic transects between Lhok $\mathrm{Nga}$ and south eastern off Calang, mainly during the night, but continuing south eastward to Sibolga they tended to be less frequent. Typical pelagic fish schooling in this shallow area is showed in Figure 10. The fishes on the shelf appeared to scatter in the daytime and tend to stay close to the bottom. This was in accordance with the fact that pelagic fishes were frequently caught in the daytime fishing operations of bottom trawl. The highest traces is obtained in the water layer between $20 \mathrm{~m}$ and $40 \mathrm{~m}$. the strength of targets traced was mostly less than -45 $\mathrm{dB}$, giving indication that the targets were small pelagic fishes.
Several investigations of the fishery resources in the west coast of Sumatera have been done before the tsunami event. Among them, expedition of RN Dr. Fridtjof Nansen (Aglen et al., 1981) was the comprehensive one. Results of the acoustic observation from R/V Dr. Fridtjof Nansen expedition showed the increasing quantities of the fish north southeasternward (from Lhok Nga up to southern Sibolga) along the shelf, of which this was different oppositely with the results of the current acoustic observation. All means that there is an indication of decreasing fish stock, which may be caused by the rapid increase of fish net fishery, in areas of the eastern and southern of Sibolga.

Although fish were observed acoustically all over the study area, no attempt was made to calculate abundance and biomass. There are two reasons to this decision. First, the acoustic survey of Baruna Jaya VIII was not designed with the specific objective to estimate distribution and abundance of pelagic fish resources in the affected areas. Due to time constraints and all the other tasks of the survey, the track was more designed for multibeam acoustic mapping of sea bottom, ROV studies, geological and environmental studies. Secondly, Baruna Jaya VIII was equipped with a very small pelagic trawl ( $5 \times 5 \mathrm{~m}$ opening), not fit for the sampling of pelagic fish species. During the survey four attempts to sample proposed fish layers were unsuccessful. Bawal Putih I only had a bottom trawl, and could not be used to sample pelagic species. Consequently, there was no confirmation of species and size composition of the observed 


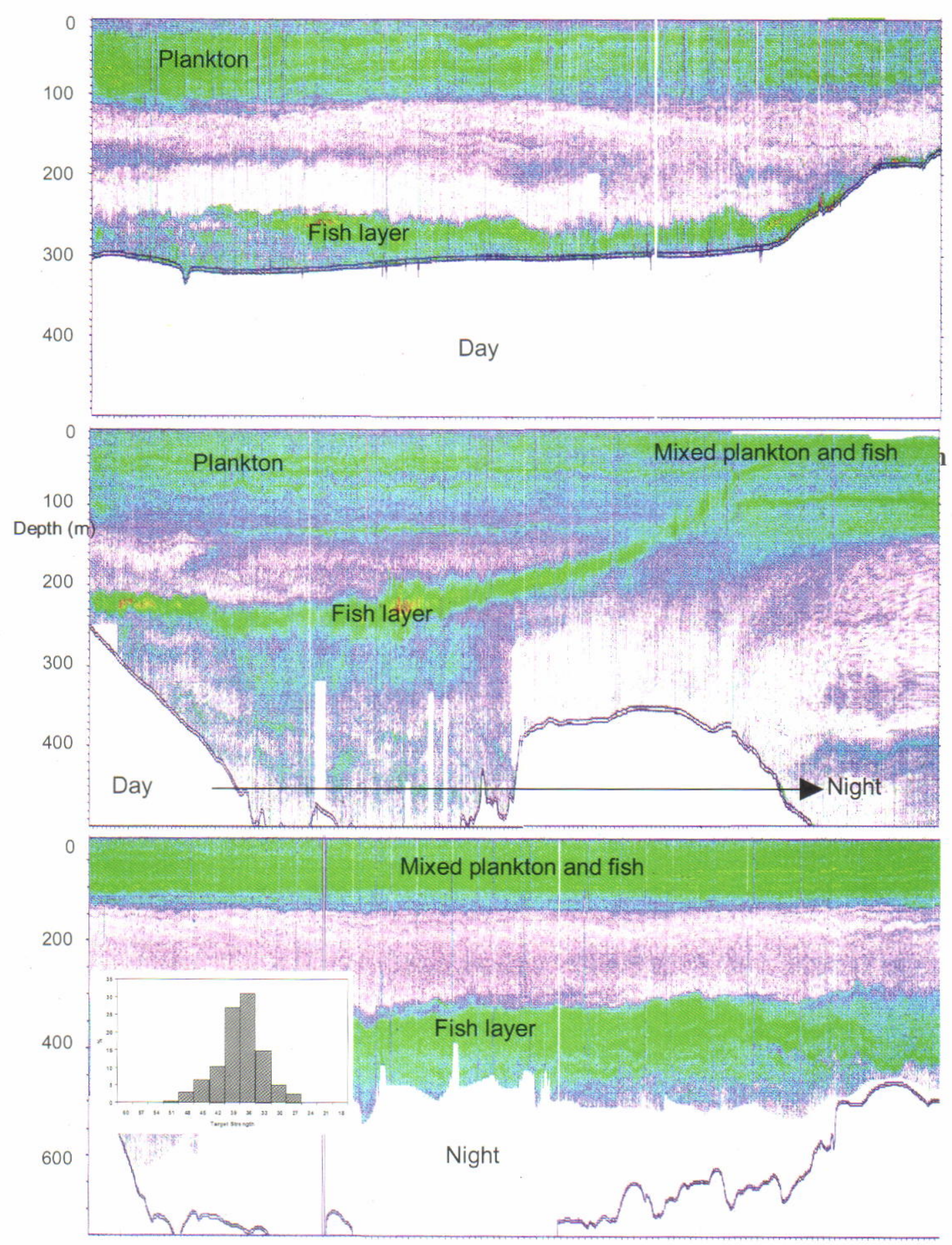

Figure 5. Echograms (15 nmi) showing fish layers observed off Meulaboh with Baruna Jaya VIII; comparison between day and night. In a) and b) the same type of layer is shown to migrate towards the surface, whereas in c) is a deeper fish layer is shown, with no signs of diurnal changes in vertical distribution, and which were found all over the deepest part of the study area. 


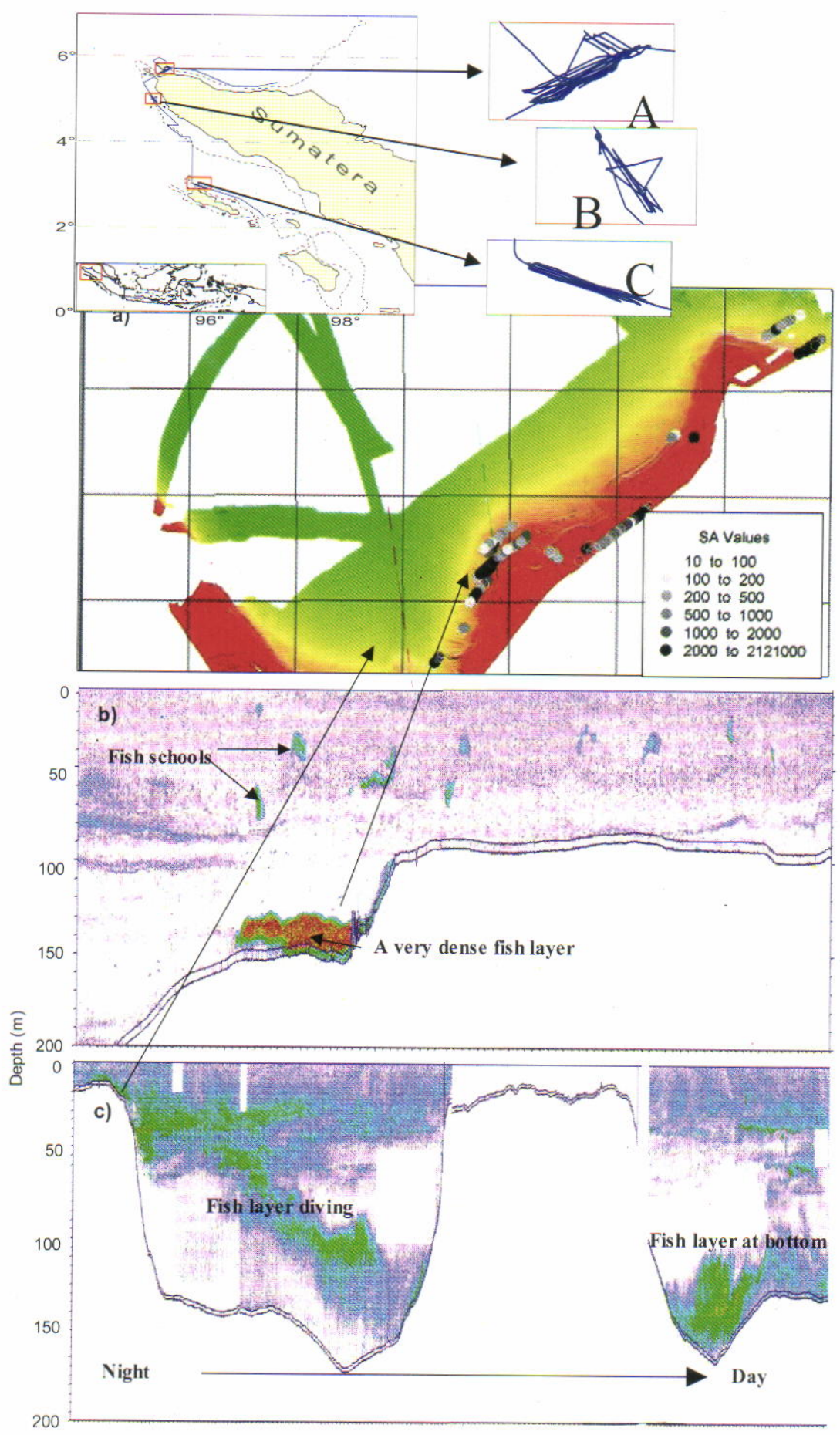

Figure 6. a) Distribution and density of fish schools from observed with Baruna Jaya VIII off Banda Aceh related to the bottom topography coming from the multi beam acoustic survey; In b) it is shown an example echogram of the observed fish schoals; and in c) it is shown example echogram of fish layer off the shelf in the Benguela strait, which is migrating towards the bottom in the morning. 

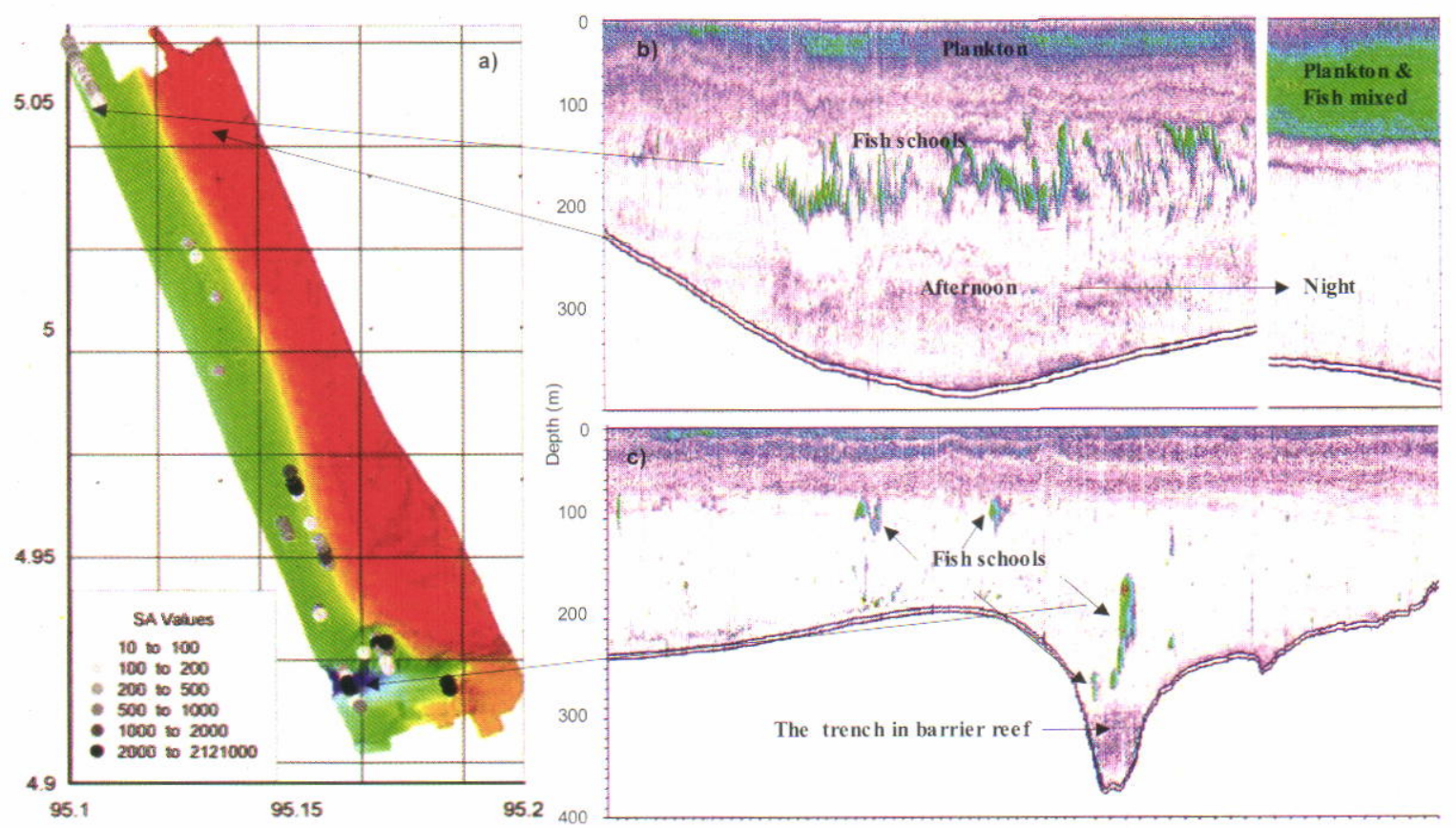

Figure 7.

a) Distribution and density of fish shoals from observed with Baruna Jaya VIII off Lhok $\mathrm{Nga}$ barrier reef related to the bottom topography coming from the multi beam acoustic survey. In b) it is shown an example echogram of the observed fish shoals, and in c) it is shown example echogram of fish layer off the shelf in the Benguela strait, which is migrating towards the surface in the afternoon and mixing with plankton in the right.

resources. Such information is necessary for estimating abundance. For future studies a larger trawl effective is clearly needed.

The acoustic method used for fish abundance estimation may be subjected to some errors. The source of errors of an acoustic estimate may be classified in two main categories. The first concerns error of the estimate, which includes spatial sampling error (the way we conduct our sampling). The second category includes the more technical aspects concerning the equipment, transmission of the sound and the target strength. The sources of errors may again be classified by their way of affecting the estimate, either randomly or systematically. One major problem pertaining to the pelagic species is related to the ensuring that the whole distribution area has been covered. The waters off Aceh west coast encloses a large area and it is impossible to cover all potential areas of distribution in a single survey. When estimating the abundance of populations of fish with schooling behaviour, the shadowing effect must always be considered as a potential source of error. When fish schools, the $S_{A}$-values are no longer proportional to fish density, but rather too low. This problem increases when the schools become larger. The present estimates are not corrected for the shadowing effect, but it is not very likely that this will have seriously affected the abundance estimates, since schools of pelagic fishes in the west coast rarely form schools dense or large enough for this to be a major source of error. 


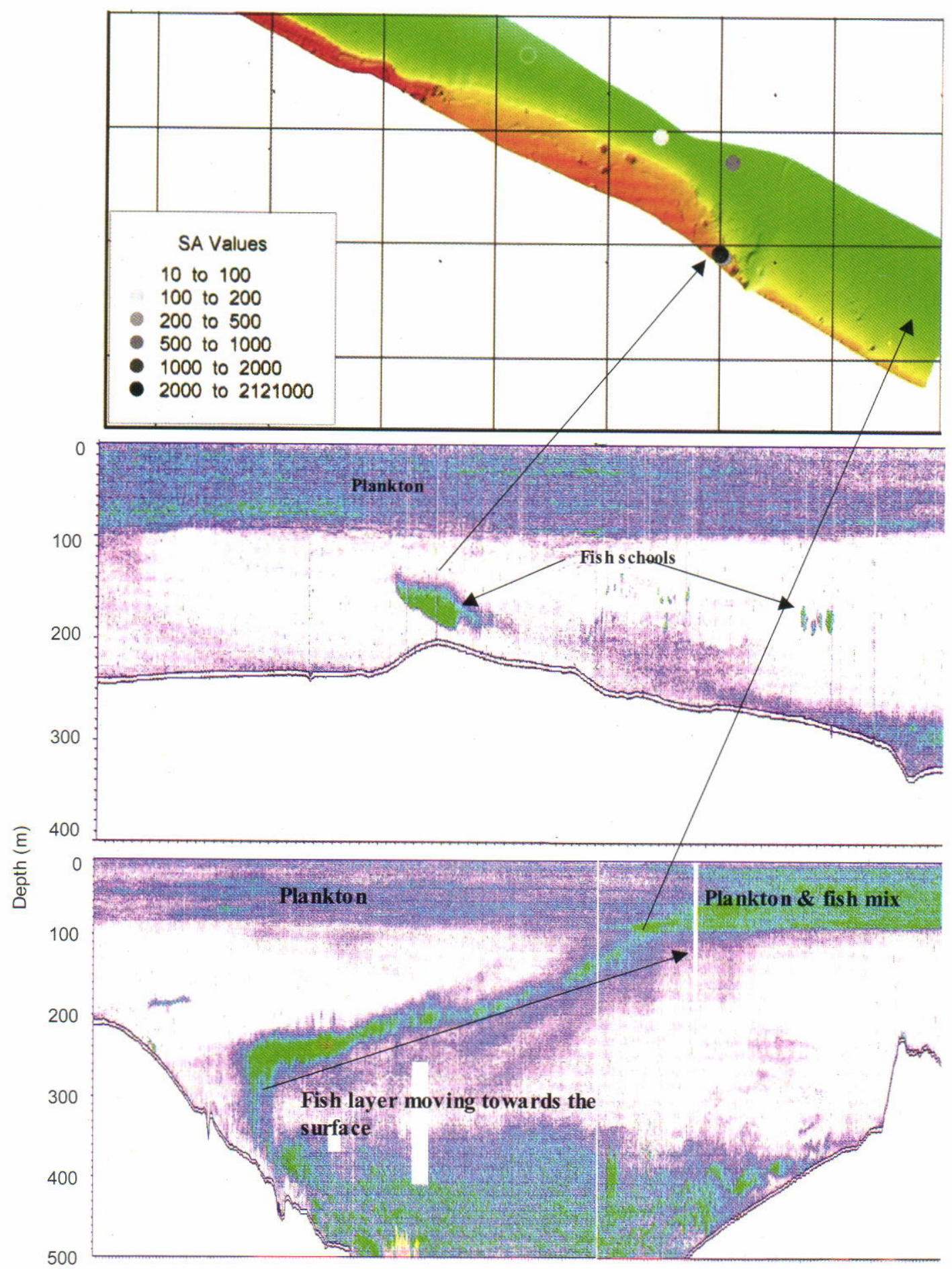

Figure 8a. a) Distribution and density of fish shoals from observed with Baruna Jaya VIII off Simeuleu related to the bottom topography coming from the multi beam acoustic survey, In b) it is shown an example echogram of the observed fish shoals, and in c) it is shown example echogram of fish layer observed migrating towards the surface after leaving Simeuleu, when it was getting dark. 


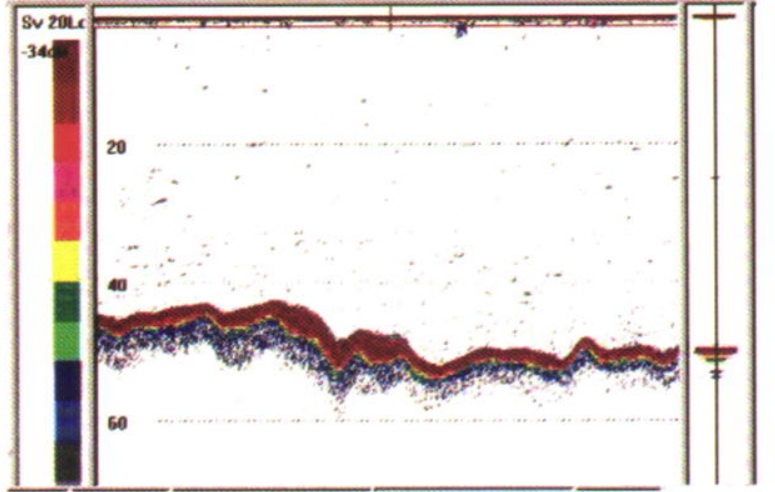

(A)

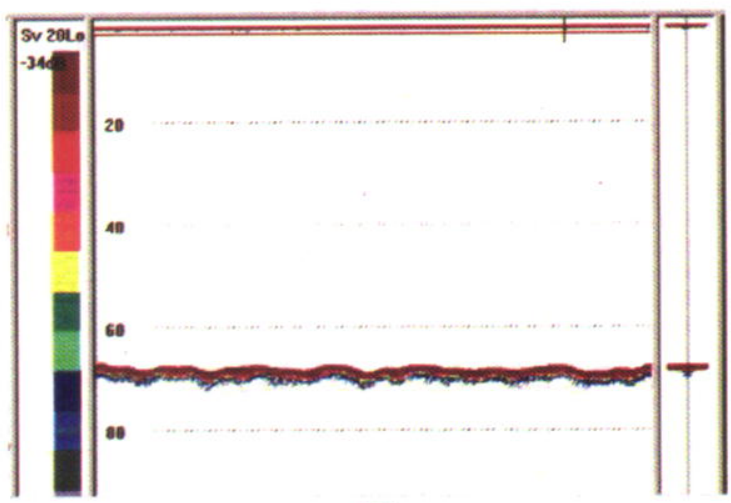

(B)

Figure $8 \mathrm{~b}$. Cypical of bottom features on the shelf areas in $(A)$ northern part of the survey area and (B) the southern part of the survey area.

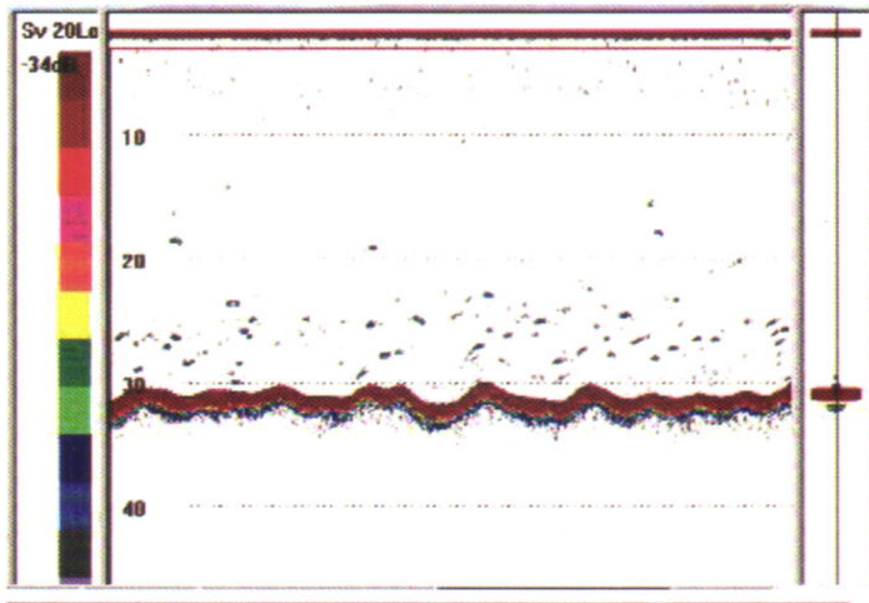

$52.38 m$

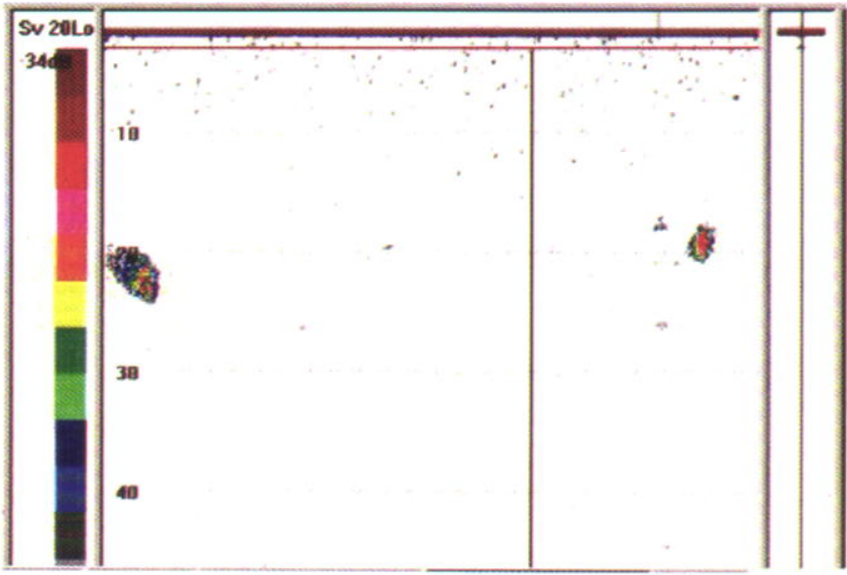

Figure 9. Typical of fish shoals in the survey area. 


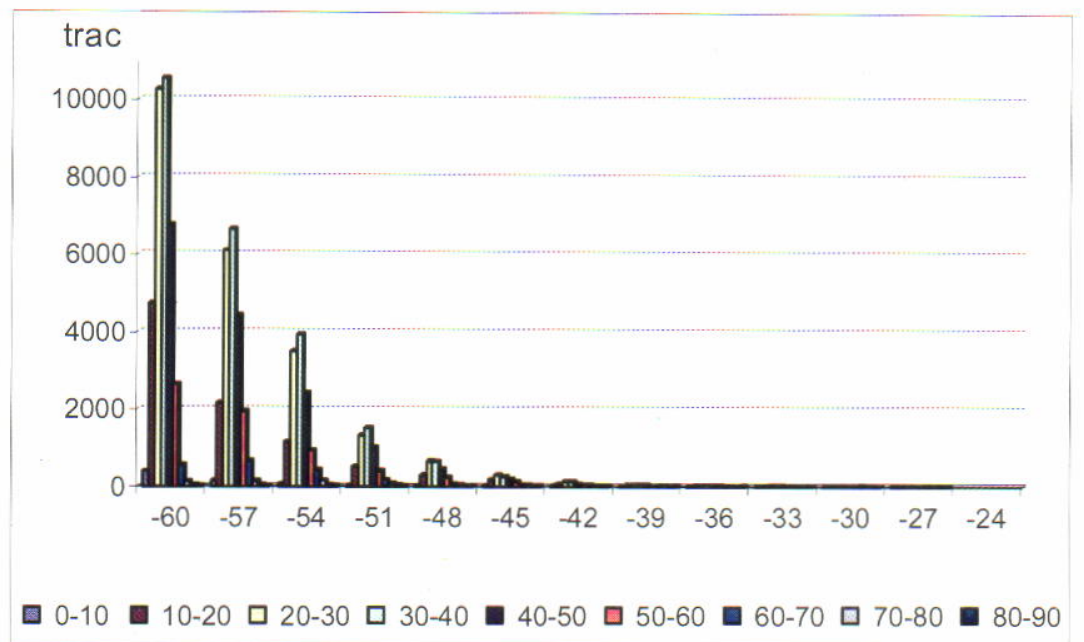

Figure 10. Distributions of traced targets along the survey tracks of R/V Bawal Putih I.

\section{CONCLUSION}

Fish aggregations appeared in high density layers in deep waters all over the study area. One species migrates vertically with the diurnal cycle (300 to $0 \mathrm{~m}$ depth). Another stays in the deep (300 to $500 \mathrm{~m}$ ) regardless of the diurnal cycle. In all three areas that were mapped in detail with multibeam echosounder, fish schools occurred in relation to topographic features such as shelf edges and deep valleys.

The results of the investigation indicate that the western Aceh waters have considerable fish resources, but the potential for exploitation is still not colculated yet. The biomass of pelagic resources should be estimated with echosounder and sonars in combination with biological sampling. To find the best season for stock assessment one has to study the stock dynamics related to seasonal changes.

\section{REFERENCES}

Aglen, A., L. Foyn, \& O. R. Godo. 1981. A Survey of the marine fish resources of the north and west coast of Sumatra-August 1980. Report on surveys with the R/V Dr. Fridtjof Nansen. Institute of Marine Research. Bergen. 1981.

Burczynsky, J. 1982. Introduction to the use of sonar system for estimating fish biomass. FAO Fisheries Technical Paper No.119. Rome: FAO.

Engas, A. \& E. Ona. 1987. Day and night fish distribution pattern in the net mouth area of the bottom sampling trawl. Development in fisheries acoustic. International Council for the Exploration of the Sea 189: 123-127.

Foote, K., H. Knudsen, G. Vestnes, D. MacLennan, \& E. J. Simmonds. 1987. Calibration of acoustic instruments for fish density estimation: a practical guide. Amsterdam: International Council for the Exploration of the Sea.

Knudsen, H. P. 1989. Bergen echo integrator: an introduction. ICES Document C.M. 1989/B: 9.

MacLennan, D. N. 1990. Acoustical measurement of fish abundance. Journal of the Acoustical Society of America 87 (1): 1-24.

Misund. 1987. Sonar observation of schooling herring: school dimensions, swimming behavior, and avoidance of vessel and purse seine. Development in fisheries acoustic. International Council for the Exploration of the Sea 189: 167-175.

Orlowski, A. 1998. Acoustic methods applied to fish environmental studies in the Baltic Sea. Fisheries Research 34: 227-237.

Slotte, A., K. Hansen, J. Dalen, \& E. Ona. 2004. Acoustic mapping of pelagic fish distribution and abundance in relation to a seismic shooting area off the Norwegian west coast. Fisheries Research 67: 143-150.

Thorne, R. E., J. B. Hedgepeth, \& J. A. Campos. 1987. The use of stationary of hydro acoustic transducers to study diel and tidal influences of fish behaviour. Development in fisheries acoustic. International Council for the Exploration of the Sea 189: 167-175. 
